\title{
EMPREGO DE QUATRO EXAMES IMUNOLÓGICOS NA DETERMINAÇÃOO DA PREVALÊNCIA DA DOENÇA DE CHAGAS NOS GARIS DO SERVIÇO DE LIMPEZA URBANA DO DISTRITO FEDERAL
}

\author{
Douglas L. Tinoco, Mônica P. Garcia, Liana Lauria-Pires, \\ Jaime M. Santana e Antonio R. L. Teixeira.
}

\begin{abstract}
A pretalência da infecçâo chagásica em 368 garis do Serviço de Limpeza Urbana (SLU) do Distrito Federal foi inicialmente indicada pelos exames de bemaglatinaçao e imunofliorescência, quando encontron-se $32,1 \%$ e $47.6 \%$ de resultados positios, respectivamente, para cada exame. Em vista das discrepâncias obsernadas, utilizou-se o teste cutâneo com o antigeno T12E para esclarecimento do diagnústico em $15,5 \%$ dos que tinbam apenas um teste sorologico positivo. O teste cutâneo foi positito em 38,6\% dos garis. A análise dos resultados de 183 garis mostrou $47 \%$ dos casos com tres exame's concondantes positivos. Mais 19.7\% ticeram dois exames concordantes positivos. Porém, 33,3\% dos garis timbam apenas um dos thês exames positio. Empregon-se também o "immunoblot" na tentatia de esclarecer o diagnóstico nos 61 casos com apenas um resultado positivo. Foram encontrados $37,5 \%$ (3/8) dos casos positios pela bemaglutinaçao, $11,5 \%$ (3/26) pelo teste cutaneo. e apenas $3,7 \%$ (1/27) pela imunoflaorescência. Após a adição desses casos positions pelo "immunoblot", o total de chagásicos passou a ser de 129, on seja, 35\% dos garis da amostra estudada.
\end{abstract}

Palauras-chates: T. cruzi. Infeccaio bumana Sorologia. Prota de pele de bipersensibilidade retardada.

Vários programas de campo foram implementados visando o estudo da evolução natural da Doença de Chagas no Brasil "i $10: 1$. Esses estudos trouxeram informaçòes importantes sobre índices de morbidade $e^{2}$ mortalidade da doença crônica que repercute na saúde das pessoas infectadas pelo Trypanosoma crizi muitos anos ou décadas após a fase aguda. Não obstante os longos periodos de observação que esses estudos requerem, foram obtidos conhecimentos importantes sobre a história natural da doença de Chagas em áreas endêmicas.

Em vista da necessidade de excluir variáveis que interfeririam na evolução natural da doença, foi iniciado o estudo longitudinal da doença nos garis do SLU do Distrito Federal. Assim, a partir de 1988, iniciou-se um programa de atendimento médico aos garis, onde inexiste a transmissão da infecçâo via

Laboratório Multidisciplinar de Pesquisa em Doença de Chagas, Universidade de Brasília, Brasília-DF.

Os resultados deste estudo foram apresentados como requisito parcial para obtenção do Título de Mestre do Dr. Douglas L.Tinoco, Universidade de Brasília, 1992.

Endereço para correspondência: Dr. Antonio RL Teixeira, CP 04685, CEP 70919-970, Brasília, DF Fax: (061) 273-4645.

Recebido para publicação em 25/01/95. inseto-vetor. A decisão de proceder o estudo nessa categoria de trabalhadores urbanos foi tomada em virtude do conhecimento de que os garis do SLU foram recrutados nas áreas rurais de diversos municípios dos estados vizinhos, onde ocorre a transmissào ativa do 7 . cruzi pelo triatomíneo. Em adiçào, o estudo longitudinal de longa duraçâo seria viabilizado pelo fato de que os garis têm estabilidade no emprego e, portanto, baixa evasão.

A primeira etapa desse trabalho consistiu na identificação dos garis chagásicos. Em vista da discrepância de resultados obtidos nos exames sorológicos de hemaglutinação e de imunofluorescência, utilizamos o teste cutâneo de hipersensibilidade tardia contra antigeno do parasito e o "immunoblot" para definir aqueles casos com apenas um daqueles exames positivo. Nesta primeira publicaçào, relatamos resultados de exames imunológicos empregados para identificar os garis chagásicos do SLU de Brasília.

\section{MATERIAL E MÉTODOS}

Amostragem. Esse estudo contou com 332 garis entre 21 e 71 anos de idade. Todos esses individuos assinaram o Termo de 
Tinoco DL, Garcia MP, Lauria-Pires I, Santana JM, Teixeira ARL. Emprego de quatro exames imunológicos na determinação da prevalência da doenç̧a de Chagas nos garis do SLU do Distrito Federal. Revista da Sociedade Brasileira de Medicina Tropical 29:33-40, jan-fev, 1996.

Conhecimento de Risco voluntariamente, dando consentimento formal para submeter-se aos exames preconizados. Em seguida, era preenchida ficha de captação de dados relacionados à epidemiologia, história familiar, exames clínico, eletrocardiográfico e laboratoriais. Os dois últimos eram repetidos uma semana depois.

Colbeita de sangue. Foi colhido $10 \mathrm{ml}$ de sangue venoso de cada gari, em vacutainer descartável. O sangue era deixado à temperatura ambiente e o soro era colhido após a coagulação e centrifugação. Uma alíquota de soro era misturado $\mathrm{com}$ glicerol $(25 \%)$ e estocado a $-20^{\circ} \mathrm{C}$. A segunda alíquota era mantida a $4^{\circ} \mathrm{C}$ até o momento do uso.

Imunofluorescência indireta. O antígeno usado consistiu de formas epimastigotas de $T$. cruzi do estoque Ernestina, crescidas em meio LIT' acrescido de soro fetal bovino a 5 por cento. As formas de cultivo eram colhidas em fase exponencial de crescimento e lavadas 4 vezes em PBS, pH 7.2. Na última lavagem as células eram mortas com formol a 1 por cento $(\mathrm{v} / \mathrm{v})$ e deixadas a $4^{\circ} \mathrm{C}$, durante $12 \mathrm{~h}$. Após lavagem em PBS eram ressuspensas em água destilada, para obter-se concentração final de $10^{\prime}$ epimastigotas $/ \mathrm{ml} ; 5 \mu l$ desse antígeno era dispensado em compartimentos de lâminas de vidro. O teste de imunofluorescências consistiu na deposição de 10 l de cada diluição do soro sobre o antigeno da lâmina, e encubação em câmara úmida, durante $30 \mathrm{~min}$ a $37^{\circ} \mathrm{C}$. A lâmina era lavada 3 vezes em PBS e secada ao ar livre. Em seguida, depositava-se sobre o antígeno na lâmina a diluição do conjugado (Cappel Laboratories, USA e Calbiochem, West Germany) que dava uma reação francamente positiva com soro padrão positivo, e totalmente negativa com soro padrão negativo. Então, procedia-se incubação e lavagem, como feito anteriormente. As lâminas eram montadas com lamínula sobre glicerina tamponada, pH 9.6, e observadas em microscópio de epifluorescência, modelo Axiophot da Carl Zeiss. Uma reação positiva era indicada pela presença de cor verde-maçà brilhante delineando a silhueta do parasito. Considerouse positiva a reação com título maior que 1:20.

Hemaglutinação indireta. Hemácias do grupo 0 e Rh- eram colhidas de doador com testes sorológicos negativos para a infecção pelo $T$. cruzi. O sangue era misturado com soluçào de Alsever $(1: 1 \mathrm{v} / \mathrm{v})$ e mantido na geladeira a $4^{\circ} \mathrm{C}$. Para preparar $100 \mathrm{ml}$ da solução de Alsever pesava-se 2,05g de glicose, $0,89 \mathrm{~g}$ de citrato de sódio e $0,42 \mathrm{~g}$ de cloreto de sódio. O pH era ajustado para $6.1 \mathrm{com}$ ácido cítrico. Após esterilização por filtração a solução era mantida a $4^{\circ} \mathrm{C}$.

O antígeno usado era obtido de formas epimastigotas de T. cruzi, colhidas do meio LIT. Após lavagem em PBS, as células eram suspensas em água destilada e rompidas após cinco ciclos de congelamentos e descongelamentos sucessivos. Em seguida, o lisado era centrifugado a $12000 \mathrm{~g}$ x $25 \mathrm{~min}$ a $4^{\circ} \mathrm{C}$. O sobrenadante colhido com pipeta era o antigeno solúvel usado para sensibilizaçào das hemácias. O teor de proteínas do antígeno era determinado pelo método de Lowry".

A suspensão de hemácias em solução de Alsever era lavada três vezes em PBS, pH 7.2, e eram tratadas com ácido tânico a 1:40.000. As hemácias tanizadas eram incubadas a $37^{\circ} \mathrm{C}$ durante $15 \mathrm{~min}$, com agitaçōes ocasionais. Após três lavagens em PBS, pH 7.2, as células eram ressuspensas em $20 \mathrm{ml}$ de $\mathrm{PBS}, \mathrm{pH}$ 6.4. A essa suspensão de hemácias tanizadas era adicionada a quantidade de $1 \mathrm{mg}$ de proteína do antígeno solúvel de $T$. cruzi, em agitação. A absorção do antígeno na superficie das hemácias se dava durante $30 \mathrm{~min}$ a $37^{\circ} \mathrm{C}$. Após essa incubação as células sensibilizadas eram lavadas em PBS e o sedimento era ressuspenso em soro normal a 1\% ("pool" de soros controles, negativos para a infecção pelo $T$. cruzi), diluído em $\mathrm{NaCl} 0,15 \mathrm{M}$.

A reação de hemaglutinação ${ }^{5}$ foi feita em placa de 96 poços (Titertek, Linbro). Os soros eram previamente inativados a $56^{\circ} \mathrm{C}$, durante $30 \mathrm{~min}$. Inicialmente, colocava-se $50 \mu \mathrm{l}$ de soro normal a $1 \%$ em cada poço da placa e, em seguida, 50 1 de cada soro teste na primeira fila da policubeta. A diluição dupla era feita com micropipeta de 8 ou 12 canais. Finalmente, acrescentava-se a cada poço da placa $50 \mu l$ da suspensão de hemácias sensibilizadas. Essa era selada com plástico para evitar evaporação e encubada a $37^{\circ} \mathrm{C}$ durante $2 \mathrm{~h}$. Um resultado positivo era indicado pela formação de um tapete de hemácias revestindo o fundo do poço, diferentemente do resultado negativo onde a deposição era punctiforme. O título de anticorpos era dado pela recíproca da diluição mais alta do soro. Considerou-se positiva a reação com título maior que $1: 8$. 
Tinoco DL, Garcia MP, Lauria-Pires L, Santana JM, Teixeira ARL. Emprego de quatro exames imumologicos na determinaçäo da prevalência da doença de Chagas nos garis do SLU do Distrito Federal. Revista da Sociedade Brasileira de Medicina Tropical 29:33-40, jan-fet, 1996

Teste cutâneo. O antígeno usado no teste cutâneo para diagnóstico da infecção chagásica foi produzido no Laboratório Multidisciplinar de Pesquisa em Doença de Chagas, Universidade de Brasilia'ti. Esse antigeno foi obtido de formas epimastigotas do clone T12E do estoque Ernestina de Tr cruzi, selecionado entre vários estoques do parasito pela capacidade de produzir enduraçào nos tecidos de coelho chagásico. Utilizou-se a dose de $50 \mu \mathrm{g}$ de proteina desse antígeno, suspenso em $100 \mu 1$ de PBS, injetada na pele do antebraço do indivíduo. Um resultado positivo era indicado pela reaçào endurada no local, medindo $1 \mathrm{~cm}^{2} 48 \mathrm{~h}$ após a injeção.

"Immunoblot". O antígeno solúvel (AS) usado neste teste foi obtido de formas epimastigotas do estoque Ernestina de $T$. cruzi. As células em fase exponencial de crescimento eram colhidas do meio LIT por centrifugação e lavadas em PBS, pH 7.2. O sedimento era, então, suspenso em PBS (1:12 $\mathrm{p} / \mathrm{v}$ ) contendo $2 \mathrm{mM}$ de para-metil-sulfonilfluoreto (PMSF) e sódio dodecil sulfato (SDS) a $1 \%(\mathrm{p} / \mathrm{v})$. Após a lise total dos parasitos pela ação do detergente iônico, o homogeneizado era centrifugado a $100000 \mathrm{~g}$ x $10 \mathrm{~min}$, a $4^{\circ} \mathrm{C}$. O sobrenadante era o AS colhido com pipeta de Pasteur. O teor de proteínas do AS era determinado pelo método de Lowry".

As proteínas do AS foram separadas por eletroforese ${ }^{8}$ em gel separador SDS-PAGE, cujo gradiente de concentração variava de 5 a $20 \%$. Usou-se marcadores de peso molecular da Sigma Chemical Co (B-galactosidase, fumarase, desidrogenase lática, e triose fosfato isomerase) para identificar a $\mathrm{Mr}$ das proteínas do AS. Em seguida, as bandas de proteinas separadas pela mobilidade eletroforética foram transferidas do gel para membrana de nitrocelulose ${ }^{15}$. Os sítios de reatividade inespecífica na nitrocelulose foram bloqueados com leite desnatado a $5 \%$ (p/v) em tampão Tris- $\mathrm{NaCl}$ (TBS), $\mathrm{pH} 7.5$, durante $2 \mathrm{~h}$ à temperatura ambiente. Fitas da membrana de nitrocelulose com $3 \mathrm{~mm}$ de largura eram encubadas com diluiçôes 1:400 dos soros testes, e após $18 \mathrm{~h}$ eram lavadas exaustivamente em TBS, durante $30 \mathrm{~min}$. Então, eram incubadas com anticorpo de coelho anti-IgG humana conjugada à peroxidase (Sigma Chemical $\mathrm{Co}$ ), diluído 1:400, durante $2 \mathrm{~h}$. Após cinco rinsagens, as bandas de proteínas nas fitas de nitrocelulose eram reveladas com 4-cloro-naftol, em solução de metanol a $2 \%$ em Tris-HCl $0,05 \mathrm{M}$, pH 7.4 , e $\mathrm{H}_{2} \mathrm{O}_{2}$ a $30 \%$, durante 10min. As bandas reveladas na nitrocelulose eram fotografadas ou guardadas embrulhadas em papel de aluminio para protegê-las do efeito evanescente da luz.

Análise estatistica. Foi determinado o intervalo de confiança para cada proporçà pela fórmula

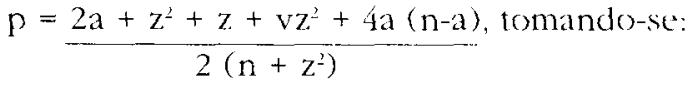

$z=1,645 ;$ sendo $a=$ número de casos positivos e, $n=$ total dos casos examinados. A regressão linear foi determinada pelo método dos mínimos quadrados.

\section{RESULTAI)OS}

A Tabela 1 mostra os resultados dos exames IF e HI em 368 garis do SLU do Distrito Federal. Foram observados 175 $(47,6 \%)$ garis com IF positiva. A 111 foi positiva, porém, em $118(32,0 \%)$ casos.

Tabela 1 - Resultados dos exames de imunofluorescencta

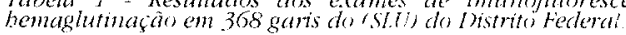

\begin{tabular}{|c|c|c|c|}
\hline Teste & Resultados* & $\mathrm{N}=\mathrm{dectsos}$ & $\%$ \\
\hline \multirow[t]{3}{*}{ Imunofluorescencia } & positives & 175 & $4 \overline{7.6}$ \\
\hline & negativo & 193 & 52.4 \\
\hline & total & 368 & 100,0 \\
\hline \multirow[t]{3}{*}{ Hemaglutinaçáo } & positivo & 118 & 320 \\
\hline & negativo & 250 & 68.0 \\
\hline & tot:l & 368 & 1000 \\
\hline
\end{tabular}
reaçăo supcrior a $1 / 8$

Os resultacios do teste cutâneo com o antígeno T12E estão apresentados na Tabela 2. Foram observados 142 (38.6\%) garis com enduração no local de injeção do antígeno (Figura 1 ) na derme superficial do antebraço, medindo mais de $1 \mathrm{~cm}$ de diâmetro. 48h apos Essas reações positivas eram bem toleradas $e$ foram identificadas facilmente pelo paciente antes mesmo de serem registradas pelo médico

Tabela 2 - Resultadrs do teste cutàneo com antigenu $772 t . \mathrm{cm}$ 368 garis do Semiço de limpeza Lrbana do Instrito Federal.

\begin{tabular}{|c|c|c|}
\hline Teste & Total cle casos & $9 / 1$ \\
\hline$\overline{\text { positivo }}$ & 142 & 386 \\
\hline negativo & 226 & 61,4 \\
\hline total & 368 & 100,0 \\
\hline
\end{tabular}

* O teste cutáneo consistiu na injecio de 5 gyg de proteina comida em 10 gll do antígeno T12F (vide texto). Intal reasio positiva era indicada pela induraços da pele, medindo mass $1 \mathrm{~cm}^{2}$, $48 \mathrm{ll}$ apos d injeçád doantigeno. 
Tinoc) DL, Garcia MP, Lauria-Pires L, Santana JM, Teixeira ARL. Emprego de quatro exames imunológicos na determinaçăo da prevalência da doença de Chagas nos garis do SLU do Distrito Federal. Revista da Sociedade Brasileira de Medicina Tropical 29:33-40, jan-fev, 1996.

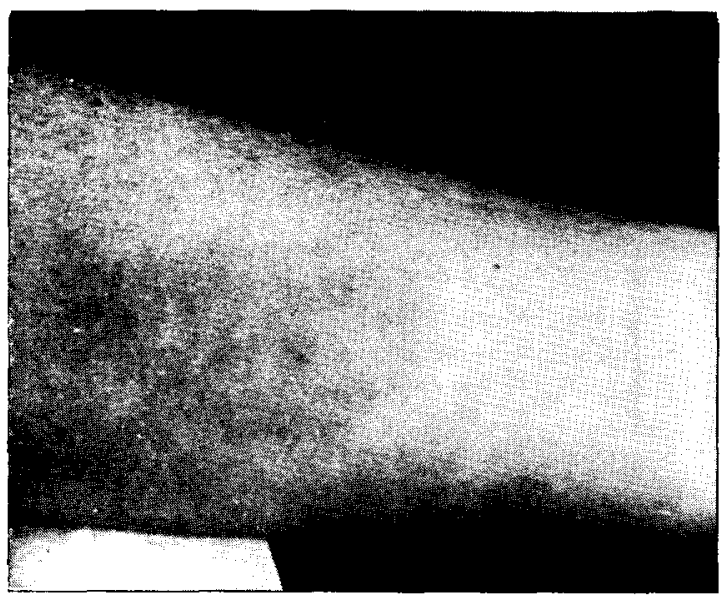

Figura 1 - Festé cutâneo como antigeno T12E deritado de um clone do estodte Ernestina do Trypanosoma cruzi Note a reacao inflamatoria endarada na pele. 48 horas apos a injecar do antigeno. observada apenas no portador da inféçao cbagásica.
As discrepancias entre os resultados do teste cutâneo T12E e dos exames IF e HI podem ser melhor apreciadas na populaça distribuida em grupos etários (Tabela 3). As maiores discrepancias foram observadas quando comparados os resultados dos exames IF e HI. Por exemplo, entre os 42 garis que tinham de 26 a 30 anos de idade haviam 17 $(4,6 \%)$ positivos pela IF, mas apenas $5(1,4 \%)$ pela HI. Não obstante as discrepancias encontradas, a análise de regressào linear mostrou correlação positiva entre os três exames empregados. Os coeficientes de correlação $(r)$ foram: HI e TC, 0,93; TC e IF, 0.94; e HI e IF, 0,83. De grande interesse, as discrepâncias com significação estatística (p< $0,05)$ foram encontradas apenas quando comparados os resultados de $\mathrm{HI}$ e IF, nas faixas etárias de 26 a 30, 36 a 40 e de 41 a 45 anos.

Os perfís de distribuição dos resultados desses exames em faixas etárias podem ser

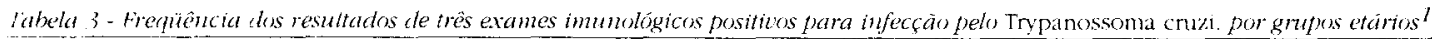

\begin{tabular}{|c|c|c|c|c|c|c|c|}
\hline \multirow{3}{*}{$\begin{array}{l}\text { Coupos } \\
\text { tários }\end{array}$} & \multirow{3}{*}{$\begin{array}{c}\text { Total } \\
\text { Colsos }\end{array}$} & \multicolumn{6}{|c|}{ Exames positivos } \\
\hline & & \multicolumn{2}{|c|}{$\mathrm{HI}$} & \multicolumn{2}{|c|}{$\mathrm{TC}$} & \multicolumn{2}{|c|}{ iF } \\
\hline & & Total & 8 & Total & \% & Total & o \\
\hline $21-25$ & 28 & 12 & 0.6 & 913 & 0.9 & 9 & 1.9 \\
\hline $26-30$ & 42 & 45 & 1.4 & 10 & 2.7 & 17 & 4.6 \\
\hline 31.35 & 47 & 16 & 4.3 & 16 & 4.3 & 17 & +.6 \\
\hline$\therefore 0-40$ & 63 & 15 & 4,0 & 24 & 6,5 & 29) & 7.8 \\
\hline $41-45$ & 48 & 16 & 4.3 & 17 & 4.6 & 25 & 0.8 \\
\hline$+60-50$ & 52 & 22 & 60 & 26 & $\neg 0$ & 20 & 78 \\
\hline $51-55$ & 43 & 21 & 5.7 & 21 & 57 & 25 & 6.8 \\
\hline $56-60)$ & 21 & 109 & 2.4 & $i 1$ & 30 & 13 & 3.6 \\
\hline 61.65 & $\therefore 1$ & 10 & 2.7 & 12 & 33 & 12 & 3,3 \\
\hline$x(7-70$ & 12 & !I & 1.3 & 1 & 4.3 & - & . \\
\hline 71 & ) & (1) & 11.3 & ()1 & 03 & $\theta 1$ & 0,3 \\
\hline rutal & 368 & 118 & 32,0 & 142 & 38.6 & 15 & 47,5 \\
\hline
\end{tabular}

Te cames de hemaglutinacio indireta. inunotuorescencia e reaço cutinea com o antigeno T12E. foram empregados.

- A anilise estatistica mostrou diferençis signifigativas $(\mathrm{P}<0,05)$ entre resultados de hemaglutinaça e de imunofluorescència, nos grupes etirios de 26 a 30 . 30 a 40 , e de 41 a 45 anos.

apreciados na Figura 2. Nota-se que o teste HI ipresentou indices mais baixos de prevalência da infeccão que os demais. O TC ocupou uma posição intermediária, e a if apresentou os indices de prevalência mais elevados. Todavia, a tendência ascendente da curva de prevalência da infecção até os 50 anos de idade, e sua queda a partir desta faixa etária, está presente em cada um dos testes empregados.

A Tabela 4 mostra o total cumulativo de garis que tiveram pelo menos um dos exames positivo. Cerca de $183(49,6 \%)$ garis tiveram um ou mais exames positivos.
Tabela 4 - Prevalencia de testes imunologicos positivos para infeccalo pelo Trypanosoma cruzi. em 368 trabalhadones do Sevvico cle Limpeza Libana do Distrito Federal

\begin{tabular}{lcc} 
Trabalhadores & $0 \%$ & Total \\
\hline Positivos & 49.6 & 183 \\
Negativos & 50,4 & 185 \\
\hline
\end{tabular}

"Os resultados positivos săo cumulativos, obtidos por IF, HI e TC.

A Tabela 5 apresenta a análise das discrepâncias entre os resultados desses exames. Verifica-se que apenas 86 (47\%) casos tiveram os três testes concordantes. Em adição, $36(19,7 \%)$ casos tiveram dois testes concordantes. Os $61(33,3 \%)$ garis restantes tiveram apenas um teste positivo: $\mathrm{HI} \mathrm{com}$ 
Tinoco DL, Garcia MP, Lauria-Pires L, Santana JM, Teixeira ARL. Emprego de quatro exames imunológicos na determinação da prevalência da doença de Chagas nos garis do SLU do Distrito Federal. Revista da Sociedade Brasileira de Medicina Tropical 29:33-40, jan-fev, 1996.

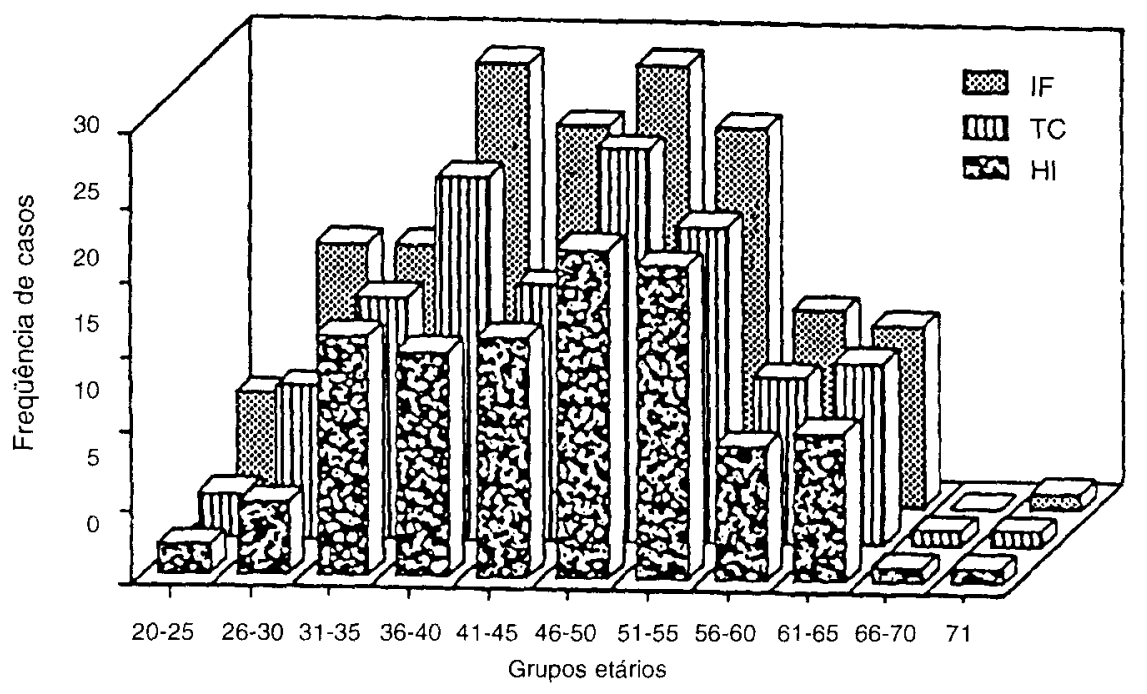

Figura 2 Frequência de resultados de exames imnuologicos positios para infeçäo pelo Trypanosoma cruzi. na amostragem de 368 garis do Senico de Limpeza Urbana do Distrito Federal.

4,3\%; IF com 14,8\% e "TC com 14,2\%. Em resumo, 61 garis tinham um teste imunológico positivo, em discordância com os demais negativos.

\begin{tabular}{|c|c|c|}
\hline Testes immologicos & $\%$ & Total \\
\hline \multicolumn{3}{|l|}{ rếs testes positivos } \\
\hline IF. HI TC & 47.0 & 80 \\
\hline dois itstes positivos & 19.7 & 36 \\
\hline $\mathrm{HI}<\mathrm{IF}$ & 9.0 & 16 \\
\hline HI & 6.8 & 12 \\
\hline IF E TC & 4.5 & 68 \\
\hline (un leste positive) & 33.3 & 61 \\
\hline IF & 14.8 & 27 \\
\hline TC & 14.2 & 26 \\
\hline $\mathrm{HI}$ & 4.3 & 08 \\
\hline
\end{tabular}
discordancia com os dematis.

A Tabela 6 mostra resultados do "immunoblot" nos 61 casos que tiveram só um dos exames positivos. Essa análise confirmou apenas um $(3,7 \%)$ caso positivo entre os 27 sugeridos pela IF. Aquele exame confirmou três $(11,3 \%)$ dos 26 casos positivos com o TC. Entretanto, três $(37,5 \%)$ dos oito casos positivos com $\mathrm{HI}$ foram confirmados com o "immunoblot".
Tabela 6. Analise pele "immunoblot" de 61 soros gue apresentaram apenas um exame position.

\begin{tabular}{|c|c|c|c|}
\hline $\begin{array}{c}\text { Exame } \\
\text { Imunológico }\end{array}$ & $\begin{array}{c}\text { Calsos } \\
\text { posituvos }\end{array}$ & $\begin{array}{l}\text { Confirmados } \\
\text { Immunolylet }\end{array}$ & 翟 \\
\hline Imunofluorescencia & 27 & 01 & 3.7 \\
\hline Teste cutâneo & 26 & 03 & 11,3 \\
\hline Hemaglutinaçà & 08 & 03 & 37.5 \\
\hline
\end{tabular}

A Tabela 7 mostra as massas relativas das bandas de proteínas antigênicas do T. cruzi identificadas pelo "immunoblot" nos sete soros com um exame positivo (resultado duvidoso) e em quatro soros com diagnóstico confirmado por três exames imunológicos positivos, concordantes. Observa-se que os soros com três provas positivas formaram mais de 10 bandas de proteinas antigênicas. Entre os sete soros duvidosos haviam três com mais de 10 bandas. Os quatro restantes tinham $8,5,3$ e 1 banda. De interesse, uma handa de $38 \mathrm{kDa}$ foi vista em seis desses soros. As bandas com $\mathrm{Mr}$ 43 e $48 \mathrm{kDA}$ foram encontradas em cinco soros duvidosos. Essas bandas também apareceram nos soros chagásicos com diagnóstico confirmado pelos três exames sorológicos empregados. A Figura 3 mostra os perfís obtidos no "immunoblot" de soros duvidosose de soros chagásicos com diagnóstico confirmado por três exames imunológicos. De maior interesse, os garis que tiveram os resultados dos exames $\mathrm{HI}$ e $\mathrm{TC}$ confirmados 
Tinoco DL, Garcia MP, Lauria-Pires L, Santana JM, Teixeira ARL. Emprego de quatro exames imunologicos na determinação da prevalência da doença de Cbagas nos garis do SLU do Distrito Federal. Revista da Sociedade Brasileira de Medicina Tropical 29:33-40, jan-fer, 1996

Tabela 7 - Massas relativas das bandas antigênicas identificactas pelo "immunoblot" em sete soros com diagnóstico duvidoso, e em quatro soros com diagnóstico confirmado por três exames imunológicos positivos"

\begin{tabular}{|c|c|c|c|}
\hline Soros & $\begin{array}{c}\text { Reagentes } \\
\text { para }\end{array}$ & $\begin{array}{c}\text { Número de } \\
\text { bandas }\end{array}$ & $\begin{array}{c}\text { Massas relativas } \\
\text { (Hr. em kDa) }\end{array}$ \\
\hline A & $\overline{\mathrm{IF}}$ & 03 & 48,$5 ; 38: 26,6$ \\
\hline B & & 12 & $120 ; 118 ; 109 ; 105 ; 76.5 ; 48,5 ; 43 ; 38: 28 ; 26,6: 25$ \\
\hline $\mathrm{C}$ & TC & 05 & $47 ; 43 ; 38 ; 28 ; 26,6$ \\
\hline $\mathrm{D}$ & & 01 & 26,6 \\
\hline $\mathrm{F}$ & & 12 & $120 ; 118 ; 112 ; 105 ; 88 ; 76.5 ; 72 ; 53 ; 48.5 ; 43: 38 ; 26.6$ \\
\hline $\mathbf{F}$ & HI & 08 & $105 ; 76.5: 72 ; 53 ; 48,5 ; 43 ; 38 ; 26.6$ \\
\hline G & & 12 & $120 ; 118 ; 105 ; 88 ; 76,5 ; 48,5 ; 43 ; 38 ; 28 ; 26,6$ \\
\hline H. I, J, L & IF, HI. TC (4) & 12 & $120: 118 ; 112 ; 105 ; 76.5 ; 48.5 ; 43 ; 38 ; 26.6 ; 25$ \\
\hline
\end{tabular}

* Fra considerado duvidoso o resultado de um exame positivo e dois negativos no mesmo soro. IF, imunofluorescência; TC, teste cutâneo com antígeno T12E; Hi hemaglutinacáo indireta.

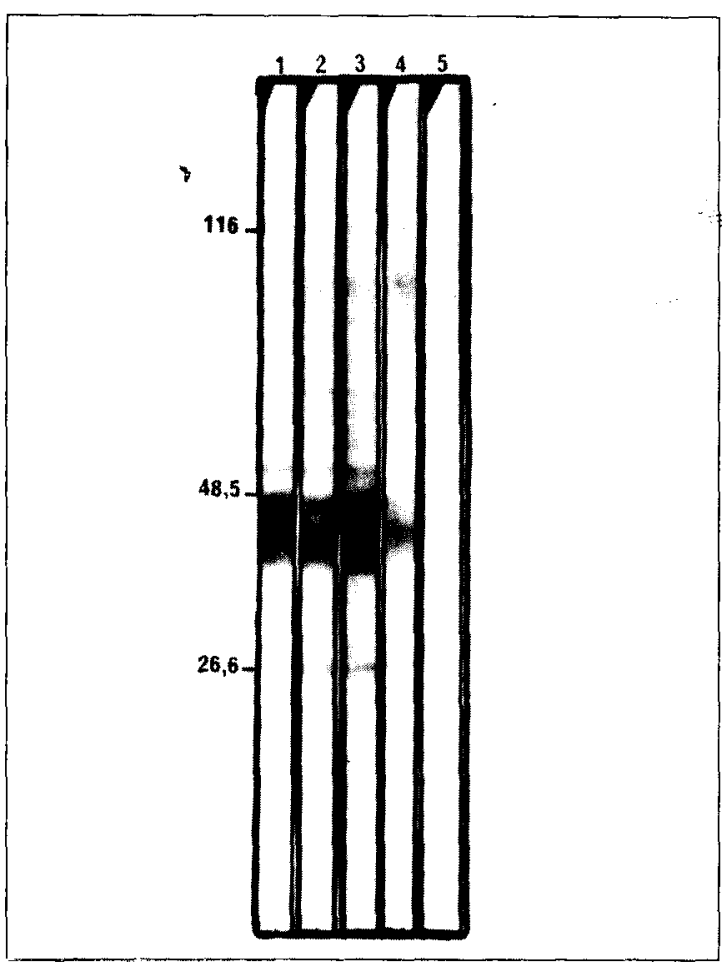

Figura 3. Perfis do "immunoblot" em soros de individuos que tinham apenas um exame imunológico position. A coluna 1 mostra várias bandas de protemas do Trypanosoma cruzi reteladas por anticompos de paciente com três exames positivos. As colunas 2. 3 e 4 mostram os perfis revelados por soro positivo com HI, TC e IF, respectivamente. A coluna 5 é o controle, com soro de individuo que tene os três testes negativos. Os numerns à esquerda representam as massas relativas (Mrj dos marcadores de peso molecular. Notam-se diversas bandas commins nas colunas de 1 a 4 . As bandas com Mr 26,6,38, $43 \mathrm{e} 48,5 \mathrm{kDA}$ foram as que mais se repetiram (vide texto).

pelo "immunoblot" tinham alterações eletrocardiográficas compatíveis com miocardiopatia chagásica crônica. $O$ único caso positivo por IF, que mostrou apenas uma banda no "immunoblot", tinha o ECG normal (dados nào apresentados).

\section{DISCUSSÃO}

Diversos autores abordaram a questão relacionada ao diagnóstico imunológico da infecção pelo $T$ cruzi, com respeito às discrepâncias de resultados de exames empregados 2371. . No estudo dos garis do SLU, a prevalência da infecção foi determinada, inicialmente, pela soropositividade dos testes de hemaglutinação e imunofluorescência. Em vista das discrepâncias observadas empregouse também o teste cutâneo com o antígeno $\mathrm{T} 12 \mathrm{E}$, derivado de um clone do estoque Ernestina de T. cruzi. Com base nessas provas imunológicas, foram obtidos percentuais variáveis de prevalência da infecçâo na coorte de 368 garis examinados no período de 18 meses. Assim, verificamos que a prevalência da infecçào variou conforme o exame tomado para diagnóstico. A soropositividade pelo exame HI foi de $32,1 \%$ e, pelo IF foi de $47,6 \%$. O teste cutâneo foi positivo em 38,6\% dos casos. As discrepâncias observadas com os testes HI e TC $(6,5 \%)$ foram menores que aquelas observadas entre $\mathrm{HI}$ e IF $(15,6 \%)$.

Em conjunto, os achados descritos acima e a apreciaçào dos trabalhos da literatura remete o leitor a uma pergunta: que fatores são responsáveis pelas discrepâncias observadas com esses exames imunológicos? Evidentemente que a origem da amostra, erro técnico, qualidade dos reagentes e variação na padronização dos métodos empregados podem influenciar a sensibilidade dos exames de imunodiagnóstico da infecção pelo $T$. cruz $i^{2} 3^{3}: 12$. Todavia, essas influências foram descartadas neste estudo, até mesmo porque os exames foram feitos em duas amostras de 
Tinoco DL. Garcia MP, Lauria-Pires L, Santana JM, Teixeira ARL. Limprego de quatro exames imunologicos na determinação da pretaiência da doença de Chagas nos garis do SLU do Distrito Federal. Retista da Sociedade Brasileira de Medicina Tropical 29:33-40, jant-fet, 1996.

soro do mesmo paciente, colhidas com intervalo de uma semana ou mais. Ademais, os resultados discrepantes foram reconfirmados com os mesmos métodos descritos. Fica claro, pois, que esses resultados falso-positivos sào devidos a réaçoes cruzadas entre antígenos de $T$. cruzi c anticorpos contra antigenos ibituosos presentes nos soros dos individuos, na populacao estudada. De fato, Vexenat mostrou gue antigenos de $I$. chizl interagem com anticorpos presentes nos soros de pacientes portaciores de calazar, teishmaniose cutâneo-mucosa. tuberculose pênígo. esquistossomose lepra, sifilis. etc.

Enfim. a partir das informacoes da literatura. analisamos os 183 casos que tiveram qualquer um los exames imunoiógicos positivo. Entre estes haviam apenas $86(47 \%)$ con resultados concordantes dos três exames empregados. Em adiçào, 36 casos (19,7\%) tiveram dois exames concordantes. Os 61 $(33,3 \%)$ garis restantes tiveram apenas um exame positivo: HI. 8 casos; TC, 26 casos; e IF, 27 casos.

Face a essas discrepâncias era impossível saber o lotal de garis portadores da infecça pelo T. cruzi. Lma resposta clara, porém, era essencial para determinar a prevalência dessa infeccáo nos garis do SLU. Por exemplo. haviam 122 garis com dois ou mais exames positivos. concordantes. Se tomarmos esse critério, 33.1\% dos garis seriam chagásicos. Entretanto. restariam 61 garis com apenas $u m$ exame positivo e os demais negativos. Com o criterio usado em inquérito soroepidemiológico, no qual a prevalência da infecçào é determinada pelo teste IF, teríamos de considerar que esses garis também sào chagásicos. Os clínicos todavia. consideram esses casos como sorologicamente duvidosos.

Em decorrência dessa análise, introduzimos o "immunoblot" na tentativa de esclarecer o cignificado real daqueles 61 casos com um exame imunológico positivo. Verificou-se que dos 27 soros positivos pelo teste IF apenas um $(3,7 \%)$ revelou bandas no "immunoblot". Dos 26 casos positivos pelo TC, três $(11,5 \%)$ foram confirmados. Em adição. dos oito casos positivos pela HI, três $(37,5 \%)$ também foram confirmados. Os 54 casos restantes nào revelaram bandas no "immunoblot"e, portanto, foram considerados falso-positivos. Em conciusas, o emprego dos quatro exames descritos aqui permitiu identificar 129 chagásicos com pelo menos dois resultados positivos, ou seja, $35 \%$ da amostra estudada. O desvio entre este percentual de positividade e HI foi de $-2,9 \%$; com 'TC foi de $3,6 \%$, e com IF foi de $12,6 \%$.

\section{SUMMARY}

seropositivity for Trypanosoma cruzi infection was studied in 368 street-sweepers of the SLU, Federal District. Brazil. with the aid of baemaghatination. imminofluorescence and. also, a delayed-type skin test to the parasite T12E antigen. It shoued 32.1\%, 42.1\% and 38.6\% positive results. respecticely for cach assay. Among these, boucter. ant a a were pusitive with each of bree exams performed. In addition, 19.7\% were positive with two out of three exams performed. The remaining $33.3 \%$ sera vielded one positive result ont of three exams employed and uere submitted to the immunoblot assay. This analysis confirmed 3 cases $37.5 \%)$ positive by bemmaglatination. $3(11.5 \%)$ positive by skin test. and I (3.7\%) positice hy immunofiuorescence. At the end of the analysis, it was shoun that 129 (35\%) individuals vielded at least tuo positue assays and. therefore, thev should be considered as T. cruzi-infected inditiduals

Key words: Hhman T. cruzi infection. Serology Delayed-type skin bypersensitility.

\section{AGRADECIMENTOS}

Aos colegas do Serviço Médico do SLU/DF, pela assistência técnica. Aos Professores Celso Chiarine e Eduardo Freitas da Silva, Universidade de Brasilia, pela análise estatística.

\section{REFERÊNCIAS BIBLIOGRÁFICAS}

1. Camargo EP. Growth and differentiation in Typanosoma chizi. I. Origin of metacyclic trypanosomes in liquid media. Revista do Instituto de Medicina Tropical de São Paulo 6:93$100,1964$.

2. Camargo ME. Fluorescent antibody test for the serodiagnosis of American trypanosomiasis. Technical modification emploving preserved culture forms of Trypanosoma crizi in a slide test. Revista do Instituto de Medicina Tropical de São Paulo, 8:227-232, 1966.

3. Camargo ME, Rebonato C. Cross-reactivity in immunoflorescence test for Trypanosoma and Leishmania antibodies. A simple inhibition 
Tinoco DL, Garcia MP, Lauria-Pires L, Santana JM, Teixeira ARL. Emprego de quatro exames imunológicos na determinação da prevalência da doença de Chagas nos garis do SLU do Distrito Federal. Retista da Sociedade Brasileira de Medicina Tropical 29:33-40, jan-fet', 1996.

procedure to ensure specific results. The American Journal of Tropical Medicine and Hygiene 18:500-505, 1969.

4. Castro CN. Influência da parasitemia no quadro clínico da Doença de Chagas. Tese de Mestrado, Universidade de Brasillia, Brasília, DF, 1978.

5. Cerisola JA, Chaben MF, Lazzari JO. Test de hemaglutinacion para el diagnóstico de la enfermedad de Chagas. Prensa Medica Argentina 49:1761-1767,1962.

6. Dias JCP. Doença de Chagas em Bambuí, Minas Gerais, Brasil. Estudo clínico-epidemiológico a partir da fase aguda, entre 1940 e 1982. Tese de Doutorado, Faculdade de Medicina Universidade Federal Minas Gerais, Belo Horizonte, 1982.

7. Guimaräes MCS, Celeste BJ, Castilho EA. Minco JR, Diniz JMP. Immunoenzymatic assay (ELISA) in mucocutaneous Leishmaniasis, Kala-Azar, and Chagas's disease: an epimastigote Tiypanosoma cruzi antigen able to distinguish between antiTrypanosoma and anti-Leishmania antibodies. American Journal of Tropical Medicine and Hygiene 30:942-947, 1981.

8. Laemmli UK. Cleavage of strutural proteins during assembly of the head of bacteriophage. Nature 227:680-685-1970.

9. Lowry OH, Rosebrough NJ, Farr AL, Randall RJ. Protein measurement with Folin fenol reagent. Journal of Biological Chemistry 193:265-275, 1951.

10. Macêdo V. Influência da exposição à reinfecção na evolução da Doença de Chagas. Estudo Longitudinal de cinco anos. Tese de Livre
Docência. Faculdade de Medicina da Universidade Federal do Rio de Janeiro, Rio de Janeiro, 1973.

11.Prata AR. Natural history of chagasic cardiomyopathy. In: American Trypanosomiasis Research. Pan-American Health Organization Publication n" 318, p. 191. 1975.

12. Prata A, Mayrink W, Sodré AG, Almeida JA. Discrepâncias relativas entre os resultados de reação de Machado e Guerreiro executados em três diferentes laboratórios. Revista da Sociedade Brasileira de Medicina Tropical 4:35-38, 1975.

13. Teixeira ARL. Hipersensibilidade tardia a antigeno de Tiypanosoma chizi. I - Estudo experimental em coelhos. Revista da Sociedade Brasileira de Medicina Tropical 28:249-257, 1995.

14. Teixeira ARL, Pereira LM. Discrepâncias entre resultados de três reações sorológicas empregadas para diagnóstico da Doença de Chagas. Revista Brasileira de Biologia 42:789-795, 1981.

15. Towbin H, Stachlin T e GordonJ. Electrophoretic transfer of proteins from polyacrilamide gels to nitrocellulose sheets: Procedure and some applications. Proceedings of the National Academy of Sciences 76:4350-4354, 1979 .

16. Vexenat ACOR. Diagnóstico Sorológico Diferencial de Infecçoes Causadas por Trupanosoma crizi, Leisbmania (Viannia) biasiliensis, Leishmania chagasi e outras Doenças Crônicas. Tese Mestrado, Universidade de Brasília, 1993. 